\title{
Orthographic Distinctiveness and Semantic Elaboration Provide Separate Contributions to Memory
}

\section{Citation}

Kirchhoff, Brenda A., Melissa L. Schapiro, and Randy L. Buckner. 2005. "Orthographic Distinctiveness and Semantic Elaboration Provide Separate Contributions to Memory." Journal of Cognitive Neuroscience 17 (12) (December): 1841-1854. doi:10.1162/089892905775008670.

\section{Published Version}

doi:10.1162/089892905775008670

\section{Permanent link}

http://nrs.harvard.edu/urn-3:HUL.InstRepos:33896766

\section{Terms of Use}

This article was downloaded from Harvard University's DASH repository, and is made available under the terms and conditions applicable to Other Posted Material, as set forth at http:// nrs.harvard.edu/urn-3:HUL.InstRepos:dash.current.terms-of-use\#LAA

\section{Share Your Story}

The Harvard community has made this article openly available.

Please share how this access benefits you. Submit a story.

\section{Accessibility}




\title{
Orthographic Distinctiveness and Semantic Elaboration Provide Separate Contributions to Memory
}

\author{
Brenda A. Kirchhoff ${ }^{1}$, Melissa L. Schapiro ${ }^{1}$, and Randy L. Buckner ${ }^{1,2}$
}

\begin{abstract}
Orthographic distinctiveness and semantic elaboration both enhance memory. The present behavioral and functional magnetic resonance imaging (fMRI) studies examined the relationship between the influences of orthographic distinctiveness and semantic elaboration on memory, and explored whether they make independent contributions. As is typical for manipulations of processing levels, words studied during semantic encoding were better remembered than words studied during nonsemantic encoding. Notably, orthographically distinct words were better recalled and received more remember responses on recognition memory tests than orthographically
\end{abstract}

\section{INTRODUCTION}

The processes engaged during the encoding of events play a key role in their memorability. For example, holding other factors equal, encoding tasks that encourage semantic elaboration result in better verbal memory than encoding tasks that encourage nonsemantic processing (Craik \& Tulving, 1975; Hyde \& Jenkins, 1969), a phenomenon often referred to as the levelsof-processing effect (Craik \& Lockhart, 1972). Neuroimaging studies that have explored the neural correlates of the levels-of-processing effect commonly note greater activity for semantic than for nonsemantic tasks in the left anterior inferior prefrontal cortex (Brodmann's area $[\mathrm{BA}] 45 / 47)$, the left posterior inferior prefrontal cortex (BA 44), and the left posterior middle temporal cortex (BA 21; Gold \& Buckner, 2002; Baker, Sanders, Maccotta, \& Buckner, 2001; Roskies, Fiez, Balota, Raichle, \& Petersen, 2001; Otten, Henson, \& Rugg, 2001; Poldrack et al., 1999; Wagner, Schacter, et al., 1998; Price, Moore, Humphreys, \& Wise, 1997; Gabrieli et al., 1996; Demb et al., 1995; Kapur et al., 1994). Moreover, activity in these regions during performance of semantic encoding tasks predicts subsequent memory for studied words (Morcom, Good, Frackowiak, \& Rugg, 2003; Baker et al., 2001; Otten et al., 2001; Wagner, Schacter, et al., 1998).

${ }^{1}$ Washington University, ${ }^{2}$ Howard Hughes Medical Institute, St. Louis, MO common words regardless of encoding task, suggesting that orthographic distinctiveness has an additive effect to that of semantic elaboration on memory. In the fMRI study, orthographic distinctiveness and semantic elaboration engaged separate networks of brain regions. Semantic elaboration modulated activity in left inferior prefrontal and lateral temporal regions. In contrast, orthographic distinctiveness modulated activity in distinct bilateral inferior prefrontal, extrastriate, and parietal regions. Orthographic distinctiveness and semantic elaboration appear to have separate behavioral and functionalanatomic contributions to memory.
These findings support the idea that these regions play an active role in memory encoding, perhaps as part of a network that enables controlled semantic elaboration.

The presence of uncommon visual patterns in words such as onyx and abyss (i.e., orthographic distinctiveness) also facilitates memory. This phenomenon is known as the orthographic distinctiveness effect (ODE). What is quite surprising and of significant theoretical interest is that orthographic distinctiveness appears to make a separate contribution to memory beyond that of semantic elaboration (Hunt \& Mitchell, 1978). Somewhat contrary to intuition, Hunt and Mitchell demonstrated that orthographically distinct (OD) words were better recalled than orthographically common (OC) words across all levels of a levels-of-processing manipulation (see Figure 1). That is, although elaborate semantic processing enhanced memorability as it does in many studies, memory for OD words was further enhanced, and the level of enhancement was similar whether words were studied under nonsemantic or semantic encoding conditions. Motivated by the possibility of a distinct contribution to memory, the present studies examined the ODE to determine whether separate functional-anatomic correlates of memory encoding could be identified beyond those previously studied in the context of semantic elaboration.

Several behavioral properties of the ODE have been characterized. OD words (e.g., onyx and abyss) are more 


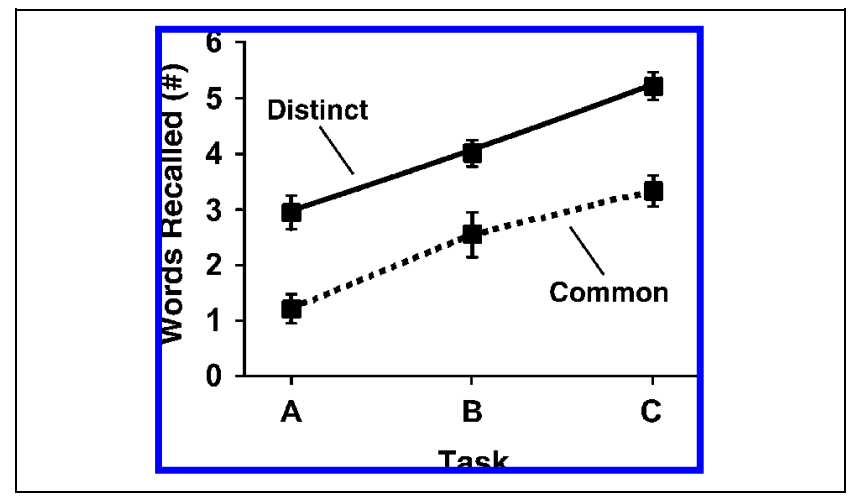

Figure 1. Free recall data from Hunt and Mitchell (1978, Experiment 2) suggest that orthographic distinctiveness has a separate influence on memory from that of semantic elaboration. Participants performed three incidental encoding tasks on OD and OC words. They (A) wrote down the letters contained in each word that were present in a set of target letters, (B) wrote down the portion of each word that they thought was unique, and (C) wrote down the first word that came to mind in response to each word. Word recall was greater for the task that encouraged semantic elaboration (C) than for either of the nonsemantic tasks (A and B). Recall of OD words was greater than recall of OC words for all tasks.

likely to have rare letter combinations, contiguous double letters, and letters extending above or below the body of the word (Zechmeister, 1969) than OC words (e.g., oaks and armor). Better memory for OD than for OC words has been found in free recall (Geraci \& Rajaram, 2002; Hunt \& Toth, 1990; Hunt \& Elliott, 1980; Hunt \& Mitchell, 1978, 1982), cued recall (Geraci \& Rajaram, 2002; Hunt \& Mitchell, 1978), recognition (Rajaram, 1998; Hunt \& Elliott, 1980; Zechmeister, 1972), and word fragment completion (Hunt \& Toth, 1990; but also see Geraci \& Rajaram, 2002; Kinoshita \& Miller, 2000). Orthographic distinctiveness has been shown to influence remember responses but not know responses on recognition memory tests (Rajaram, 1998; but see Kishiyama \& Yonelinas, in press), raising the possibility that orthographic distinctiveness may preferentially affect conscious recollection. We will revisit the issue of whether orthographic distinctiveness influences familiarity as well as recollection in the present studies.

The ODE has been proposed to depend on perceptual processing during encoding (Hunt \& Toth, 1990; Hunt \& Elliott, 1980). The ODE occurs when words are presented visually but not auditorily (Hunt \& Toth, 1990; Hunt \& Elliott, 1980), which suggests that information about the unusual visual pattern of OD words needs to be encoded for the ODE to occur. Geraci and Rajaram (2002) have proposed that the ODE depends on a high-level, comparative evaluation of a stimulus against its context. In support of this proposal, the ODE occurs when OD and OC words are presented intermixed in the same study list, but not when they are presented separately (Hunt \& Elliott, 1980). In addition, dividing attention at study can eliminate the ODE (Geraci \& Rajaram, 2002). The neural correlates of the ODE have not been previously explored.

Motivated by the intriguing possibility that orthographic distinctiveness makes a contribution to memory that is separate from that of semantic elaboration, the goals of the present studies were: (1) to examine the relationship between the influences of orthographic distinctiveness and semantic elaboration on verbal memory, and (2) to explore whether orthographic distinctiveness modulates the activity of a different network of brain regions than the network commonly engaged by manipulations of semantic elaboration. In Study 1, participants performed both semantic (abstract/ concrete) and nonsemantic (long vowel/short vowel) incidental encoding tasks on OD and OC words. Both free recall and recognition of the words were tested. Study 2 used rapid presentation event-related functional magnetic resonance imaging (fMRI) to compare the networks of brain regions engaged by orthographic distinctiveness and semantic elaboration. The results of these studies not only demonstrate that orthographic distinctiveness and semantic elaboration have separate, additive contributions to verbal memory, but also that they appear to have separate functional-anatomic correlates.

\section{RESULTS}

\section{Behavioral Study}

\section{Encoding}

Mean percent correct classification scores were 88\% (abstract/concrete common), 83\% (abstract/concrete distinct), 85\% (long vowel/short vowel common), and $76 \%$ (long vowel/short vowel distinct). Participants had significantly higher classification scores for the abstract/ concrete task $[F(1,47)=11.2, p<.01]$ and for OC words $[F(1,47)=54.4, p<.001]$. The Task $\times$ Word-type interaction was not significant $[F(1,47)=1.5]$. Mean response times were $1071 \mathrm{msec}$ (abstract/concrete common), $1128 \mathrm{msec}$ (abstract/concrete distinct), $1337 \mathrm{msec}$ (long vowel/short vowel common), and $1476 \mathrm{msec}$ (long vowel/short vowel distinct). Participants were significantly faster in their decisions for the abstract/concrete task $[F(1,47)=130.3, p<.001]$ and for OC words $[F(1,47)=$ 105.9, $p<.001]$. The Task $\times$ Word-type interaction was significant $[F(1,47)=17.0, p<.001]$, but the main effects predominated the pattern of response times. Taken together, these results suggest that the long vowel/short vowel task was more difficult than the abstract/concrete task.

\section{Recall}

After both encoding tasks and a brief distracting conversation, participants were asked to recall the words that 
they had seen during encoding. Participants recalled more words from the abstract/concrete task $[F(1,47)=$ $11.9, p<.01 ;$ Figure 2]. They also recalled more OD words $[F(1,47)=5.9, p<.05]$. The Task $\times$ Word-type interaction was not significant $[F(1,47)=1.2]$. These results replicate the findings of Hunt and Mitchell (1978) (Figure 1).

\section{Recognition}

After performance of the recall test and an additional 20 min delay, participants' recognition memory for studied words was tested using a remember/know procedure (Gardiner, 1988; Tulving, 1985). This procedure allows the identification of which recognized items were accompanied by a conscious recollection of aspects of the prior occurrence of studied items (remember responses), and which items were recognized based on a sense of familiarity in the absence of conscious recollection (know responses). Participants indicated their memory for each word by making a remember, know, new, or guess response. Participants made more remember responses (corrected for false alarms) for words presented during the abstract/concrete task $[F(1,47)=$ $61.6, p<.001$; Figure 3]. They also made more remember responses for OD words $[F(1,47)=37.7, p<.001]$. The Task $\times$ Word-type interaction was significant $[F(1,47)=5.7, p<.05]$. However, the main effects predominated the pattern of remember responses. These results parallel Hunt and Mitchell's (1978), and extend them to a recognition memory paradigm.

The proportion of know responses that participants made for all trials for each condition was also compared. The proportion of know responses for each participant is dependent on the proportion of remember responses that each participant makes (i.e., if a participant makes a remember response for a word, he/she cannot also make a know response for the same word). To correct

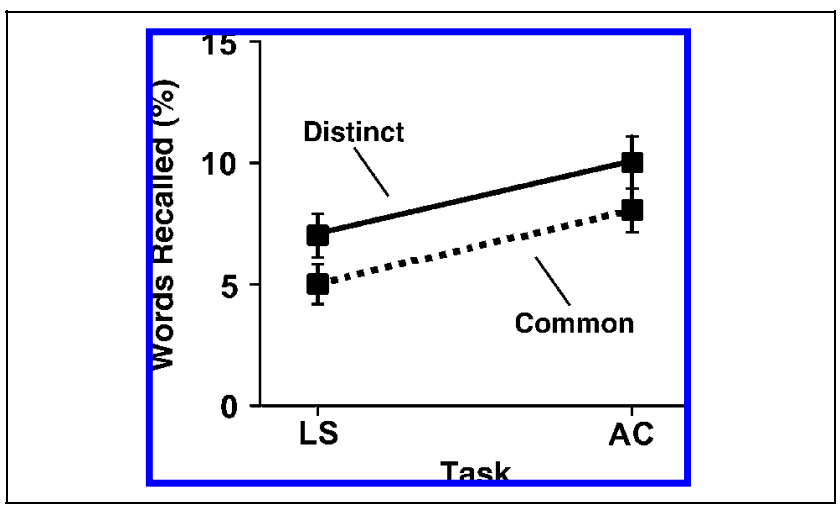

Figure 2. Paralleling Hunt and Mitchell's (1978) results, participants recalled more words from the abstract/concrete task than from the long vowel/short vowel task in the present behavioral study. They also recalled more OD than OC words for both encoding tasks. Error bars show standard error of the mean.

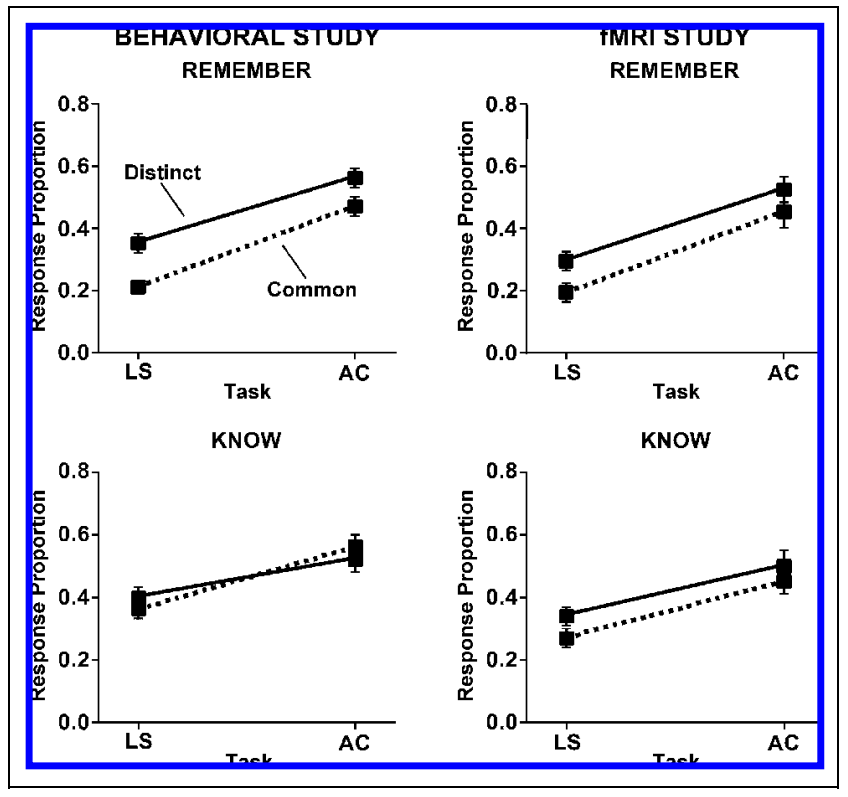

Figure 3. Performance on the recognition memory tests for the behavioral and fMRI studies. More corrected remember and corrected know responses were made for words presented during the abstract/ concrete task than during the long vowel/short vowel task in both studies. Participants also made more corrected remember responses for OD than for OC words in both studies. Although there was no difference in the number of corrected know responses given for OD versus OC words in the behavioral study, there was a trend for more corrected know responses for OD words in the fMRI study.

for the influence of remember responses on know responses, the independence remember/know (IRK) procedure was performed (Yonelinas \& Jacoby, 1995). This correction assumes that remember and know responses are independent. We used the formula [corrected $K=K$ / $(1-R)]$. Know responses were also corrected for false alarms. Participants made more corrected know responses for the abstract/concrete task $[F(1,47)=23.9$, $p<.001 ;$ Figure 3]. There was no difference between the number of corrected know responses made for OD versus OC words $[F(1,47)<1]$. The Task $\times$ Word-type interaction was not significant $[F(1,47)=2.5]$.

\section{fMRI Study}

\section{Encoding}

Functional images were acquired during four eventrelated incidental encoding runs. Participants performed the abstract/concrete task for two runs and the long vowel/short vowel task for two runs. Mean percent correct classification scores were 91\% (abstract/concrete common), 80\% (abstract/concrete distinct), 87\% (long vowel/short vowel common), and 79\% (long vowel/short vowel distinct). There was a trend for higher classification scores for the abstract/concrete task than for the long vowel/short vowel task $[F(1,24)=4.1, p=.05]$. Participants had significantly higher classification scores 
for OC words $[F(1,24)=62.3, p<.001]$. There was also a trend for a Task $\times$ Word-type interaction $[F(1,24)=$ $3.7, p=.07]$. Mean response times were $1113 \mathrm{msec}$ (abstract/concrete common), $1203 \mathrm{msec}$ (abstract/concrete distinct), $1364 \mathrm{msec}$ (long vowel/short vowel common), and $1486 \mathrm{msec}$ (long vowel/short vowel distinct). Participants were significantly faster in their decisions for the abstract/concrete task $[F(1,24)=69.6$, $p<.001]$ and for OC words $[F(1,24)=72.8, p<.001]$. The Task $\times$ Word-type interaction was not significant $[F(1,24)=2.5]$. These results are similar to the findings from the behavioral study, and suggest that the long vowel/short vowel task was more difficult than the abstract/concrete task.

\section{Recognition}

After incidental encoding, participants performed a surprise recognition memory test outside of the scanner. Participants indicated their memory for each word by making a remember, know, new, or guess response. Similar to the findings from the behavioral study, participants made more remember responses (corrected for false alarms) for words presented during the abstract/ concrete task $[F(1,24)=71.2, p<.001$; Figure 3]. They also made more remember responses for OD words $[F(1,24)=25.4, p<.001]$. The Task $\times$ Word-type interaction was not significant $[F(1,24)=2.8]$. Know responses corrected with the IRK procedure were also compared across conditions. Participants made more corrected know responses for the abstract/concrete task $[F(1,24)=24.9, p<.001$; Figure 3]. There was a trend for participants to make more corrected know responses for OD words $[F(1,24)=4.0, p=.06]$. The Task $\times$ Word-type interaction was not significant $[F(1,24)<1]$.

\section{Hypothesis-driven Regional Analyses}

Hypothesis-driven analyses were performed on four predefined regions (Figure 4). Three of these regions (left BAs 45/47, 44, and 21) were taken from a previous study conducted in our laboratory (Logan, Sanders, Snyder, Morris, \& Buckner, 2002). These regions have been shown to be more active during elaborative semantic than during shallow nonsemantic verbal encoding (Gold \& Buckner, 2002; Baker et al., 2001; Wagner, Schacter, et al., 1998; Price et al., 1997). The fourth region is the right homologue of BA 44, which served as a control region for which no effect of semantic elaboration was predicted.

Two $\times$ two repeated-measures, mixed-effect ANOVAs (Task $\times$ Word-type) were conducted to examine whether the activity of these regions was modulated by semantic elaboration and/or orthographic distinctiveness. The left BA 45/47 demonstrated a significant Task effect

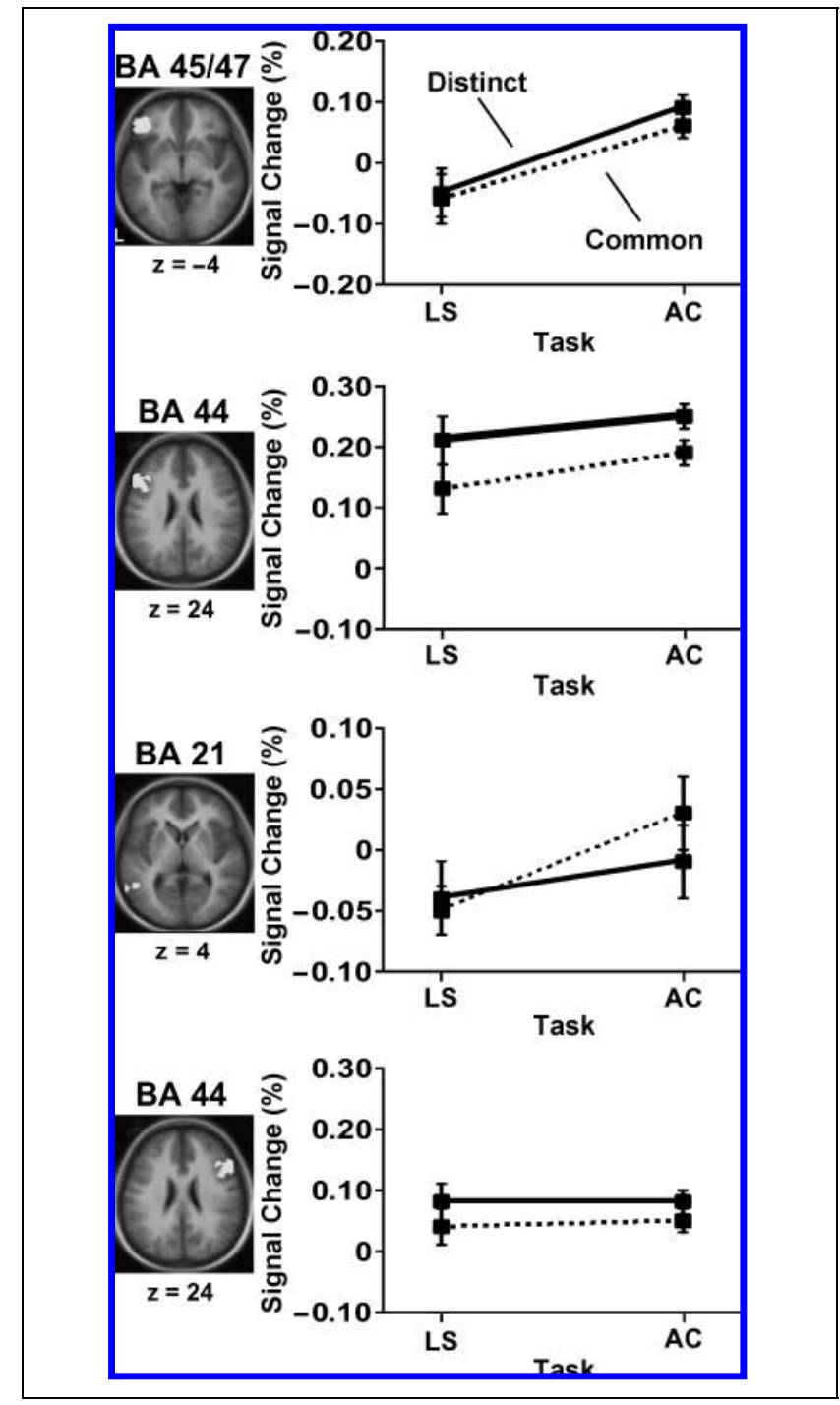

Figure 4. MR signal change from four predefined regions. Semantic elaboration and orthographic distinctiveness did not significantly modulate activity of the same regions. There was significantly greater activity during the abstract/concrete task than during the long vowel/ short vowel task for the left BA 45/47 and left BA 21, but not for the bilateral BA 44. In contrast, orthographic distinctiveness significantly modulated activity in the bilateral BA 44, but not in the left BA 45/47 or left BA 21.

$[F(1,24)=14.6, p<.001]$, but not a significant Wordtype effect $[F(1,24)=1.8]$. There was greater activity in this region during the abstract/concrete task than during the long vowel/short vowel task. The Task $\times$ Word-type interaction was not significant $[F(1,24)<1]$. In contrast, the left BA 44 did not demonstrate a significant Task effect $[F(1,24)=2.2]$. However, the activity of this region was modulated by orthographic distinctiveness. There was significantly greater activity in this region for OD words $[F(1,24)=15.7, p<.001]$. The Task $\times$ Word-type interaction was not significant $[F(1,24)<1]$. Similar to the left BA $45 / 47$, the left BA 21 demonstrated a significant Task effect $[F(1,24)=5.0$, 
$p<.05$ ] in the absence of a significant Word-type effect $[F(1,24)=2.1]$. There was greater activity in this region during the abstract/concrete task. There was a trend for the Task $\times$ Word-type interaction to be significant $[F(1,24)=3.6, p=.07]$. Similar to its left homologue, the right BA 44 did not demonstrate a significant Task effect $[F(1,24)<1]$, but did demonstrate a significant Word-type effect. There was greater activity in this region for OD words $[F(1,24)=7.3$, $p<.05]$. The Task $\times$ Word-type interaction was not significant $[F(1,24)<1]$.

\section{Exploratory Analyses of Task and Orthographic Distinctiveness Effects}

Whole-brain exploratory analyses revealed several regions with greater hemodynamic responses for the semantic (abstract/concrete) than for the nonsemantic (long vowel/short vowel) task (Figure 5). These included the left anterior dorsal prefrontal (BA 8/9), medial prefrontal (BA 9/10), left anterior inferior prefrontal (BA 45/47), bilateral insular, left anterior temporal (BA 20/21), bilateral lateral temporal (BA 21), left parietal/ temporal (BA 39), and right cerebellar cortical regions. The Talairach and Tournoux (1988) coordinates of the left BA $45 / 47(-42,30,-6)$ and left BA 21 (-56, $-48,-6)$ regions active in this comparison are similar in location to the coordinates of the a priori regions used in the hypothesis-driven analyses (see Methods for coordinates). Multiple brain regions demonstrated greater activity during the long vowel/short vowel task than during the abstract/concrete task. These regions included the bilateral anterior dorsal prefrontal (BA 9/46), bilateral posterior inferior prefrontal (BA 6), left occipitotemporal (BA 19/37), bilateral extrastriatal (BA 18/19), and bilateral medial parietal (BA 7/19) cortical regions.
Whole-brain exploratory analyses also revealed several regions with greater hemodynamic responses for OD than for OC words (Figure 5). These regions included the supplementary motor, left (BA 45/46 and 6/44) and right (BA 9) prefrontal, left frontal opercular (BA 47), bilateral extrastriatal (left BA 18, right BA 18/ 19), bilateral parietal (BA 7), and right cerebellar cortical regions.

\section{Analyses of Regions Engaged by \\ Orthographic Distinctiveness}

Six regions that demonstrated greater responses for OD than for OC words were identified from the distinct $>$ common whole-brain exploratory analysis (Figures 5 and 6). The presence of significant Task effects was explored in these regions. The Talairach and Tournoux (1988) coordinates of these regions were $-50,4,35$ (BA 6/44); -40, 29, 9 (BA 45/46); -28, -92, -11 (BA 18); 34, $-83,7$ (BA 18/19); -24, -65, 55 (BA 7); and 22, -62, 53 (BA 7). The left BA 6/44 region partially overlaps the left $\mathrm{BA} 44$ region from the hypothesis-driven analyses. In the prefrontal cortex, the left BA 6/44 demonstrated a significant Task effect $[F(1,24)=15.9, p<.001]$. There was greater activity in this region during the long vowel/ short vowel task. There was no significant Task effect in the left BA 45/46 $[F(1,24)<1]$. Neither of these regions revealed a significant Task $\times$ Word-type interaction $[F(1,24)<1]$. In the extrastriate cortex, there was no significant Task effect in the left BA $18[F(1,24)<1]$, but there was a significant Task effect in the right BA 18/19 $[F(1,24)=6.4, p<.05]$. There was greater activity during the long vowel/short vowel task in this region. The Task $\times$ Word-type interaction was not significant for either extrastriate region $[F(1,24)<1]$.

In the parietal cortex, the left and right BA 7 demonstrated significant Task effects $[F(1,24)=10.7, p<.01$;
Figure 5. Statistical activation maps show regions whose activity was modulated by semantic elaboration (A) or orthographic distinctiveness (B). Regions A (BA 6/44), B (BA 45/46), C (BA 18), D (BA 18/19), E (BA 7), and $\mathrm{F}$ (BA 7) had greater activity for OD than for OC words. Regions G (BA 45/47) and $\mathrm{H}$ (BA 21) had greater activity during the semantic than during the nonsemantic encoding task, but were not present in the OD versus OC word comparison.

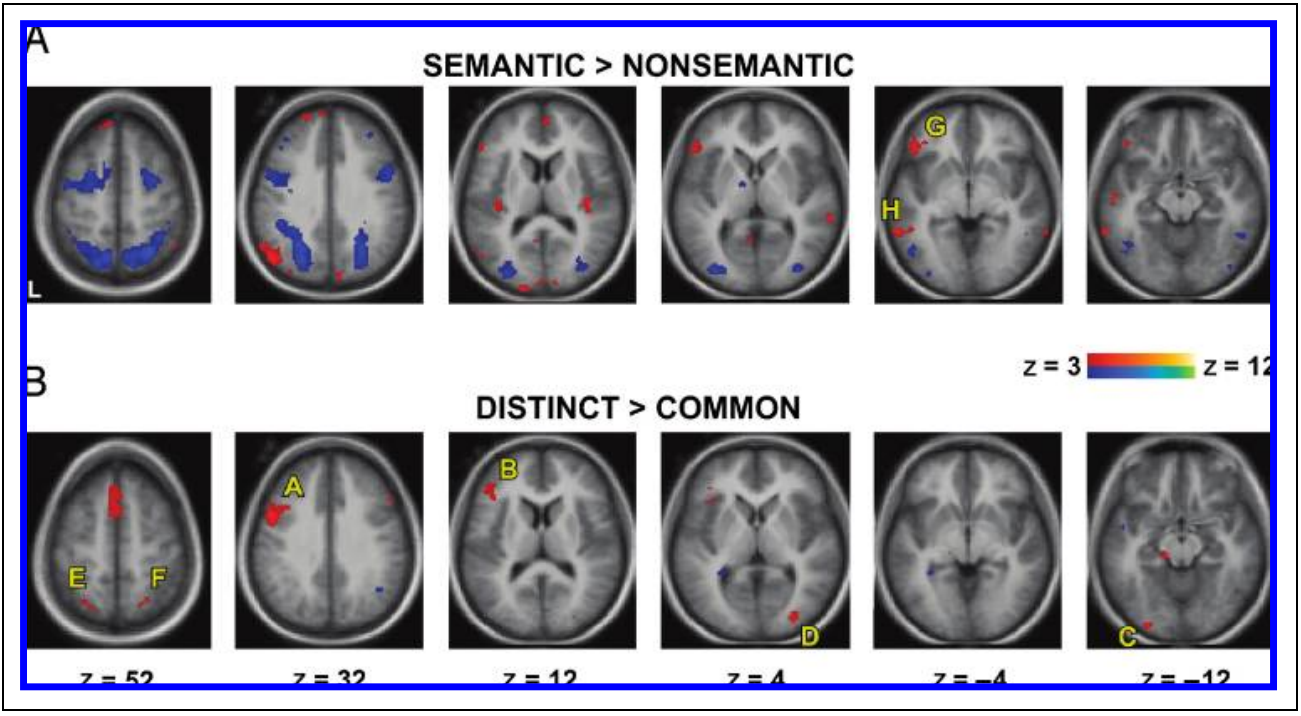


Figure 6. MR signal change data from regions that demonstrated greater activity for OD than for OC words. Regions A-F correspond to regions labeled $\mathrm{A}-\mathrm{F}$ in Figure 5. There was a greater response during the long vowel/short vowel task than during the abstract/concrete task in the left BA 6/44, right BA 18/19, and bilateral BA 7 .

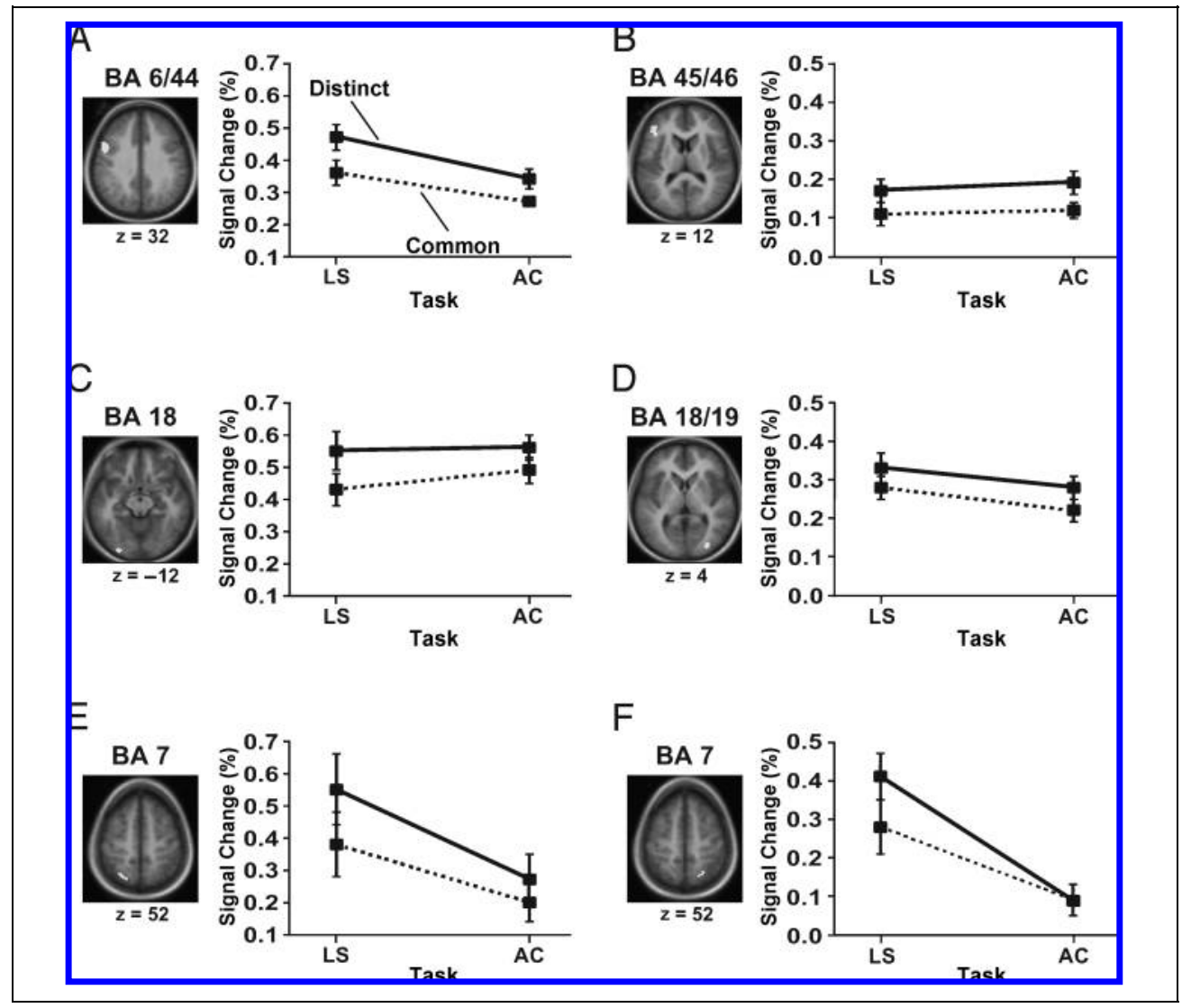

$F(1,24)=31.0, p<.001$, respectively]. There were greater hemodynamic responses during the long vowel/ short vowel task in these regions. The Task $\times$ Wordtype interaction was significant in the right BA 7 $[F(1,24)=5.4, p<.05]$. There was a greater hemodynamic response to OD than to OC words in this region during the long vowel/short vowel task $[t(24)=$ $-3.7, p<.01]$. In contrast, there was no difference in this region in the response to the two word-types during the abstract/concrete task $[t(24)<1]$. Although the Task $\times$ Word-type interaction was not significant in the left BA $7[F(1,24)=1.6]$, this region demonstrated a qualitatively similar activity pattern to that of the right BA 7. Because bilateral BA 7 regions were most active during the long vowel/short vowel task and demonstrated the greatest modulation by orthographic distinctiveness during the encoding task that emphasized phonological processes, BA 7 appears to have been preferentially engaged by phonological processes in this study.

\section{Location of Occipital Regions Engaged by Orthographic Distinctiveness}

In order to further explore the functional-anatomic correlates of the ODE, the distinct $>$ common word activation map was projected onto a cortical surface representation that displays estimates of the average locations of human retinotopically defined visual areas (Figure 7; Van Essen, 2002; Van Essen et al., 2001; http://brainmap.wustl.edu/caret). Bilateral occipital regions demonstrated greater activity for OD than for OC words (left BA 18, right BA 18/19). The left region is located in the extrastriate visual cortex just posterior to the lateral occipital central (LOC)/lateral occipital peripheral (LOP) (Tootell \& Hadjikhani, 2001), whereas the right extrastriate region is located within the LOC/LOP. The lateral occipital complex, which is thought to contribute to object recognition (GrillSpector, Kushnir, Hendler, \& Malach, 2000; Grill-Spector, Kushnir, Edelman, Itzchak, \& Malach, 1998; Malach et al., 1995), overlaps with the location of the LOC/LOP (Van Essen, 2004). This suggests that orthographic distinctiveness modulates the activity of ventral visual processing areas involved in object recognition. The left extrastriate region engaged by orthographic distinctiveness appears to be anatomically distinct from the "visual word form area," which is a left occipitotemporal region that is hypothesized to participate in the formation of abstract visual representations of letterstrings (Cohen \& Dehaene, 2004; Cohen et al., 2000; but see Price \& Devlin, 2004). It also appears to be separate from the left medial extrastriate regions that have been proposed 


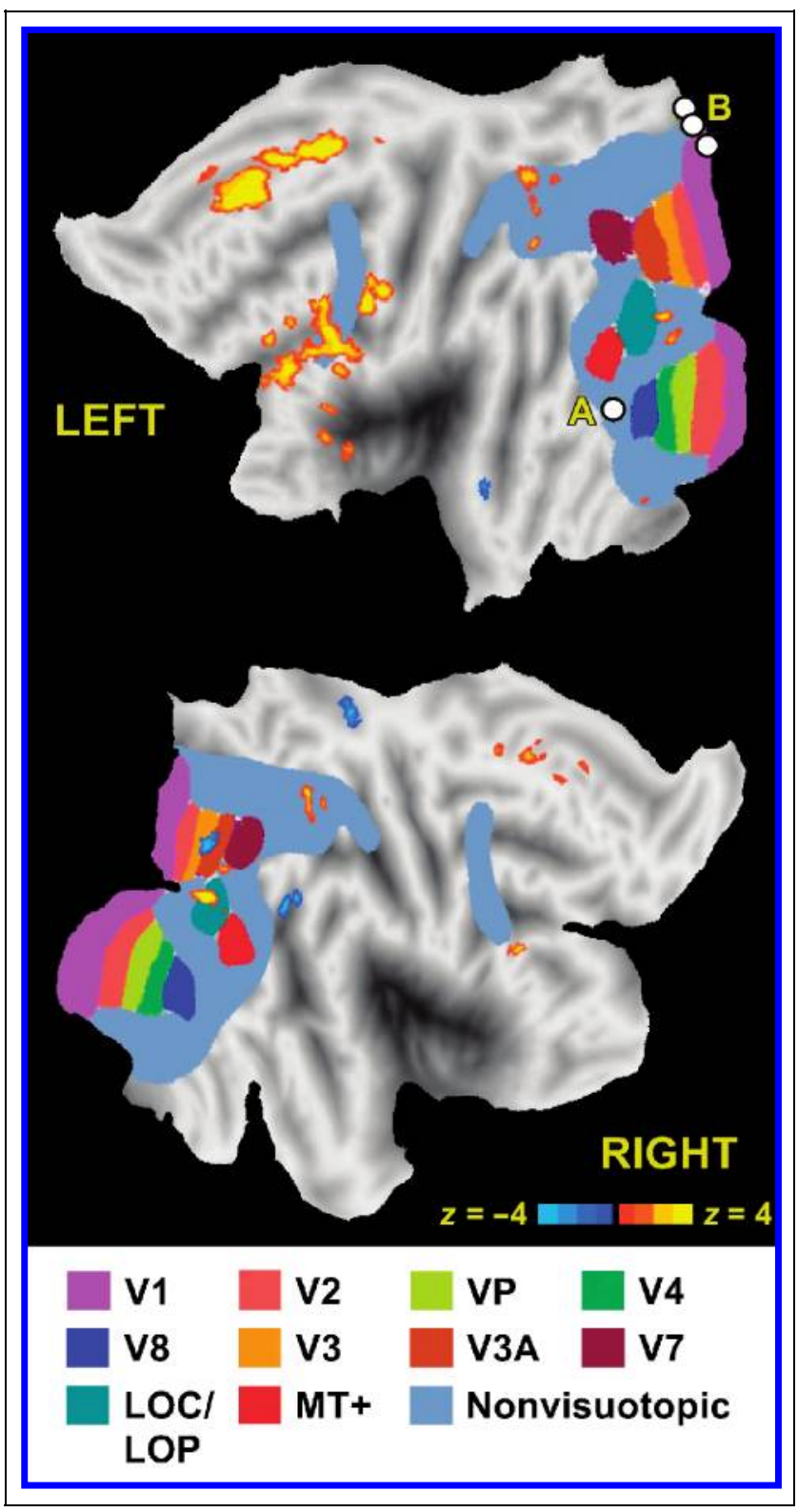

Figure 7. Cortical flat maps of bilateral extrastriate regions with greater activity in response to OD than to OC words. These regions were located posterior to the LOC/LOP in the left hemisphere and within the LOC/LOP in the right hemisphere. These regions are anatomically distinct from regions proposed to be involved in visual word form analyses in prior studies: (A) "visual word form area" and (B) left medial extrastriate.

to represent visual word forms by Petersen, Fox, Snyder, and Raichle (1990).

\section{DISCUSSION}

The present studies examined the relationship between the influences of orthographic distinctiveness and semantic elaboration on memory, and explored whether they modulate the activity of similar or distinct net- works of brain regions. The results demonstrate that orthographic distinctiveness has a separate, additive effect to that of semantic elaboration on memory. In addition, orthographic distinctiveness and semantic elaboration appear to engage separate networks of brain regions. Semantic elaboration modulated activity in left inferior prefrontal and lateral temporal regions. In contrast, orthographic distinctiveness modulated activity in distinct bilateral inferior prefrontal, extrastriate, and parietal regions. Taken together, these findings suggest that the influence of orthographic distinctiveness on memory is distinct from the often-studied influence of semantic elaboration on memory.

\section{Orthographic Distinctiveness and Semantic Elaboration have Separate, Additive Influences on Verbal Memory}

A key finding in human memory research is that, holding other factors constant, semantic elaboration enhances verbal memory (Craik \& Tulving, 1975; Craik \& Lockhart, 1972; Hyde \& Jenkins, 1969; but see also Morris, Bransford, \& Franks, 1977). The orthographic pattern of words can also affect memorability: words with distinct orthographies are better retrieved than words with common orthographies (i.e., the ODE; Hunt \& Mitchell, 1978, 1982; Hunt \& Elliott, 1980). What is the relationship between the influences of semantic elaboration and orthographic distinctiveness on memory? Data from Hunt and Mitchell (1978) (Figure 1) suggest that they may have separate contributions to memory. In the present studies, words processed during the semantic incidental encoding task were better recalled than words processed during the nonsemantic incidental encoding task for both OD and OC words, replicating prior reports of semantic elaboration's facilitatory effect on memory. Consistent with Hunt and Mitchell's findings, participants in the present behavioral study recalled more OD than OC words for both semantic and nonsemantic encoding tasks. These results suggest that the influence of orthographic distinctiveness on memory may be independent from the influence of semantic elaboration.

\section{Orthographic Distinctiveness Facilitates Conscious Recollection and May Also Enhance Familiarity}

According to dual-process models, two distinct forms of processes contribute to recognition memory performance: recollection and familiarity (Jacoby, 1991; Mandler, 1980; for review, see Yonelinas, 2002). In the present studies, participants' recognition memory for studied words was tested using a remember/know procedure (Gardiner, 1988; Tulving, 1985). Although the relation is imperfect, on average, remember responses 
serve as a measure of conscious recollection, whereas know responses reflect a feeling of familiarity in the absence of conscious recollection (Yonelinas, 2002; Yonelinas \& Jacoby, 1995). Rajaram (1998) reported more remember responses for OD than for OC words on a recognition memory test that followed intentional encoding, which suggests that orthographic distinctiveness facilitates conscious recollection. In both of the present experiments, participants made more remember responses for OD than for OC words, regardless of task. This replicates Rajaram's results, and extends them to an incidental encoding paradigm. This also supports the proposal that orthographic distinctiveness has a separate, additive influence on memory to that of semantic elaboration. Further evidence that orthographic distinctiveness facilitates conscious recollection comes from studies showing that orthographic distinctiveness facilitates free recall (Geraci \& Rajaram, 2002; Hunt \& Toth, 1990; Hunt \& Mitchell, 1978, 1982; Hunt \& Elliott, 1980) and cued recall (Geraci \& Rajaram, 2002; Hunt \& Mitchell, 1978). Also, Geraci and Rajaram (2002) found evidence that OD words are remembered better than OC words on the implicit test of word fragment completion only when participants are aware that word fragments can be completed by previously studied words. The results of the present and prior studies provide strong evidence that orthographic distinctiveness can enhance memory by facilitating participants' ability to consciously retrieve specific details about studied words and/or the processes engaged during their encoding.

Orthographic distinctiveness may also enhance word familiarity. Rajaram (1998) originally reported no difference in the proportion of know responses to OD versus OC words, which suggests that orthographic distinctiveness may not influence word familiarity. However, know responses on the remember/know procedure are likely to underestimate the influence of familiarity on recognition memory because participants respond "know" only when an item is both familiar and not recollected (Yonelinas, 2002; Yonelinas \& Jacoby, 1995). To compensate for this underestimation, the IRK procedure (Yonelinas \& Jacoby, 1995) can be used to correct know responses for the number of remember responses given. When Kishiyama and Yonelinas (in press) applied this correction to Rajaram's original data, they found more corrected know responses for OD than for OC words, which suggests that orthographic distinctiveness enhances word familiarity. Consistent with an influence of orthographic distinctiveness on memory that extends to familiarity, a trend for more corrected know responses for OD than for OC words was found in the present fMRI study. However, the behavioral study did not show this effect. There was less of a ceiling effect on remember responses for the fMRI study, which may have resulted in a better estimation of word familiarity for this study. Additional research is needed to clarify the impact of orthographic distinctiveness on familiarity.

\section{Network of Brain Regions Engaged by Semantic Elaboration}

Three left hemisphere regions (BAs 45/47, 44, and 21) commonly demonstrate greater activity during semantic than during nonsemantic processing tasks (Gold \& Buckner, 2002; Poldrack et al., 1999; Wagner, Schacter, et al., 1998; Kapur et al., 1994), and may be part of a network that contributes to semantic elaboration. The activity of these regions was hypothesized a priori to be modulated by semantic elaboration in the present fMRI study. In support of our predictions, there was significantly greater activity in the left BA 45/47 and left BA 21 during the abstract/concrete task than during the long vowel/short vowel task. The left BA 44 did not show significantly greater activity during the abstract/concrete task as predicted, although the percent signal change for this task was numerically larger than that for the long vowel/short vowel task. Orthographic distinctiveness did not modulate the activity of the left BA $45 / 47$ or left BA 21 . In contrast, the left BA 44 had a greater response to OD than to OC words. It is possible that the left BA 44 may be engaged by both semantic elaboration and orthographic distinctiveness. However, in the present fMRI study, none of the a priori ROIs that demonstrated reliable semantic elaboration effects also had their activity patterns modulated significantly by orthographic distinctiveness. These results suggest that the evaluative contextual processes thought to play a role in the ODE (Geraci \& Rajaram, 2002) are not dependent on semantic elaboration.

\section{Network of Brain Regions Engaged by Orthographic Distinctiveness}

Multiple brain regions demonstrated greater activity for OD than for OC words. None of these regions had greater activity during the abstract/concrete task than during the long vowel/short vowel task. Taken together with the results of the a priori ROI analyses, these findings suggest that orthographic distinctiveness and semantic elaboration modulate separate networks of brain regions.

The activity of three left inferior prefrontal regions (BAs 44, 6/44, and 45/46) was modulated by orthographic distinctiveness in the present fMRI study. There are multiple possible reasons for the greater hemodynamic response to OD words in these regions. One possible reason is that these regions are sensitive to the relative familiarity of the orthographic patterns of words. Binder and colleagues (2003) found greater activity in the left BA 6 for words with no orthographic neighbors (words that share all but one letter with a word are its ortho- 
graphic neighbors) than for words with many orthographic neighbors. Because OD words have lower bigram frequencies (Zechmeister, 1969) than OC words, they should also have fewer orthographic neighbors. Another possible reason is that these regions may play a role in orthographic to phonological transformations (Fiebach, Friederici, Muller, \& von Cramon, 2002; Fiez, Balota, Raichle, \& Petersen, 1999). Fiez and colleagues found greater activity in left BA 44 for words with inconsistent spelling-to-sound correspondences than for words with consistent ones. In the present study, participants made more errors and were slower to respond on OD word trials than on OC word trials during the long vowel/short vowel task, suggesting that the lower bigram frequencies of the OD words resulted in a more difficult orthographic to phonological transformation. Finally, the activity of the left inferior prefrontal cortex may have been modulated by orthographic distinctiveness because it may be sensitive to stimulus distinctiveness per se. Neuroimaging studies comparing incongruous (e.g., a head of a wrench fused onto a sheep's body) versus ordinary objects (Michelon, Snyder, Buckner, McAvoy, \& Zacks, 2003) and lowfrequency versus high-frequency words (Chee, Goh, Lim, Graham, \& Lee, 2004; Chee, Westphal, Goh, Graham, \& Song, 2003) have found greater activity in the left BA $6 / 9 / 44$ for the distinctive stimuli. Future research is needed to determine the role of the left inferior prefrontal cortex in the ODE.

Of particular interest, three of the regions engaged by orthographic distinctiveness may participate in the processing of visual information. The bilateral occipital regions that demonstrated greater activity for OD than for OC words (left BA 18, right BA 18/19) were located in the vicinity of the lateral occipital complex, a region that contributes to object recognition (Grill-Spector, Kushnir, Hendler, et al., 2000; Grill-Spector, Kushnir, Edelman, et al., 1998, Malach et al., 1995). Thus, the extrastriate visual regions that play a role in object recognition may also be sensitive to the visual patterns of words when they are distinctive. Right posterior inferior prefrontal cortex (including BA 44) is engaged by the encoding and retrieval of visuospatial stimuli (Brewer, Zhao, Desmond, Glover, \& Gabrieli, 1998; Kelley et al., 1998; Wagner, Poldrack, et al., 1998). In addition, activity levels in this region have been shown to predict subsequent memory during a task that emphasizes the visual appearance of words (case judgments; Baker et al., 2001). In the present study, the bilateral extrastriate and right inferior prefrontal regions with greater activity in response to OD than to OC words were likely involved in encoding the relatively uncommon visual patterns of the OD words. The fact that the network of regions whose activity was modulated by orthographic distinctiveness includes regions engaged by visual information processing suggests that the ODE is at least partially dependent on the analysis of the distinctive visual patterns of these words (Hunt \& Toth, 1990; Hunt \& Elliott, 1980).

How do the neural correlates of the ODE compare to the neural correlates of other distinctiveness effects that influence memory? Many studies of the effects of distinctiveness on memory have used isolation paradigms in which the primary distinctiveness of stimuli is manipulated. Primary distinctiveness refers to situations in which an item is distinctive in comparison to other recently presented stimuli (Schmidt, 1991). In isolation paradigms, memory is enhanced for words that have different visual, conceptual, or emotional features than surrounding background words (Strange, Henson, Friston, \& Dolan, 2000; von Restorff, 1933; for a review, see Schmidt, 1991). ERP studies of these paradigms have shown that there is a greater $\mathrm{P} 300$ response, which is maximal over centroparietal scalp sites, to visual and semantic isolates than to control words (Fabiani \& Donchin, 1995; Karis, Fabiani, \& Donchin, 1984). In an fMRI study of visual, semantic, and emotional isolates, Strange et al. (2000) found that emotional isolates preferentially engaged the left amygdala and the left BA 47, whereas semantic isolates preferentially engaged the left BA 46 during deep semantic encoding. There was greater activity in the right inferior prefrontal cortex (BA 45) and in bilateral extrastriate regions (BA 19) for all three types of distinctive words relative to their controls.

In contrast to studies using isolation paradigms, the present fMRI study manipulated secondary distinctiveness, which refers to situations in which distinctive items are unusual in relation to the larger context of all previous experiences (Schmidt, 1991). Other neuroimaging studies of secondary distinctiveness and memory include Michelon and colleagues' (2003) comparison of incongruous versus congruous objects, which reported enhanced recognition of incongruous objects, and greater activity for incongruous objects in bilateral inferior prefrontal (BA 6/9/44), parietal (BA 7), fusiform (BA 37), and extrastriate regions (BA 18/19).

Finally, neuroimaging studies of the word frequency effect, in which low-frequency words are better remembered than high-frequency words (for review, see Schmidt, 1991), have shown greater activity for lowfrequency than for high-frequency words in the anterior cingulate (BA 32), left fusiform (BA 37), left parietal (BA 7), bilateral inferior prefrontal (BA 6/44), and bilateral extrastriate (BA 18) regions (Chee, Goh, et al., 2004; Chee, Westphal, et al., 2003). Although the present and prior fMRI studies of distinctiveness and memory differed significantly in the types of stimuli used and the forms of distinctiveness that they manipulated, they all demonstrated greater activity in right inferior prefrontal ( BA 44) and bilateral extrastriate $(\sim \mathrm{BA} 18 / 19)$ regions for distinctive stimuli. This suggests that these regions may play important roles in processing stimulus distinctiveness, and that these regions may be sensitive to both primary and secondary distinctiveness. 


\section{METHODS}

\section{Stimulus Development}

\section{Participants}

Thirty native English-speaking volunteers participated (age range 19-37, mean age 22; 18 women). Informed consent for all studies was obtained using procedures approved by Washington University's Human Studies Committees.

\section{Stimuli}

A normed list of OD and OC words was created for use in the present behavioral and fMRI studies. A list of 305 words that were thought to be orthographically distinct was constructed. Each OD word was matched for starting letter, number of letters, and word frequency (Kucera \& Francis, 1967) with a word that was thought to be orthographically common. OD words with frequencies of 0 were matched with $\mathrm{OC}$ words with frequencies of 1 . Twenty pseudowords were also constructed, half of which were designed to be OD, to be used as a form of negative control.

\section{Tasks}

Participants rated the visual distinctiveness of each stimulus on a 5-point scale on which $1=$ "quite common" and $5=$ "very weird." Participants also indicated (1) whether they thought each item was a real word, and (2) whether they knew the meaning of each item to ensure that participants recognized the OD words as being real, meaningful words. "Yes" responses were given a score of 1 , and "no" responses were given a score of 0 .

\section{Behavioral Study}

\section{Participants}

Fifty-six native English-speaking new volunteers participated. Data from 48 were included in the behavioral data analyses (age range 18-28, mean age 20; 39 women). Data from the remaining participants were excluded from analyses because they did not meet a $65 \%$ correct performance criterion for the long vowel/short vowel task. This performance criterion was used so that data from only those participants who were able to perform the long vowel/short vowel task with reasonable accuracy were analyzed.

\section{Stimuli}

Ninety-six OD words and 96 matched OC words were selected from the normed word list for use in this study. For this subset of selected words, the mean distinctive- ness rating for the OD words was significantly greater (2.90) than the mean distinctiveness rating for the OC words $[1.71 ; t(95)=33.0, p<.001]$. The mean real score for the OD words was 0.99 , and the mean real score for the OC words was 1.0. Although numerically very similar, the real scores for the two word-types were significantly different $[t(95)=-2.3, p<.05]$. The mean meaning score for the OD words was 0.98 , and the mean meaning score for the OC words was 0.99 . The meaning scores for the two word-types were also significantly different $[t(95)=-5.6, p<.001]$.

\section{Tasks}

For the abstract/concrete task, participants decided whether each word represented an abstract or concrete entity (Demb et al., 1995). For the long vowel/short vowel task, participants decided whether each word was a long or short vowel word (Gold \& Buckner, 2002). A word is a long vowel word whenever any of the sounds "a," "e," "i," "o," or "u" are present anywhere in the word, no matter which letter(s) forms the sound. For example, the word "weight" would be classified as long vowel because it contains the "a" sound. Participants were presented with two lists of 48 words, and performed one task for each word list. Each list consisted of 24 OD words and 24 matching OC words. Two buffer words were presented before and after each list. Responses to buffer words were not analyzed. Each word was presented centrally for $2000 \mathrm{msec}$, followed by $500 \mathrm{msec}$ of fixation. A plus sign was presented centrally during fixation. Task and stimulus presentation order was counterbalanced across participants. Participants indicated their responses by making right-handed keypresses.

After a brief distracting conversation, participants were asked to recall the words they saw during performance of either encoding task. Participants were instructed to write down at least 20 words, and were given a maximum of $10 \mathrm{~min}$ for recall. After an additional delay of $20 \mathrm{~min}$, participants performed a surprise recognition memory test. The 96 words shown during incidental encoding and 96 new words (half OD and half matched OC) were presented. The words presented during the first task that a participant performed and half of the new words were presented during the first half of the recognition test, followed by the remaining old and new words. Participants indicated their memory for each word by making a remember, know, new, or guess response. They were instructed to make a remember response if they were able to consciously recollect aspects of a word's prior presentation during the study session. They were instructed to make a know response if they recognized that a word was previously encountered during the experiment, but could not consciously recollect aspects of its prior occurrence. Participants were also told to make new responses to words they 
did not recognize, and to use the guess response only as a last resort.

\section{fMRI Study}

\section{Participants}

Thirty-one native English-speaking new volunteers participated in the fMRI study. All were right-handed and reported no significant neurological history. Data from 25 were included in the behavioral and functional neuroimaging data analyses (age range 18-29, mean age 22; 14 women). Data from two participants were excluded due to excessive motion. Data from an additional four participants were excluded because they did not meet a $65 \%$ correct performance criterion for the long vowel/ short vowel task.

\section{Stimuli}

One hundred thirty-five OD words and 135 matched OC words were selected from the normed word list for use in this study. For this subset of words, the mean distinctiveness rating for the OD words was significantly greater (2.97) than the mean distinctiveness rating for the OC words $[1.72 ; t(134)=45.0, p<.001]$. The mean real score for the OD words was 0.99 , and the mean real score for the OC words was 1.0. Although numerically very similar, the real scores for the two word-types were significantly different $[t(134)=-4.2$, $p<.001]$. The mean meaning score for the OD words was 0.96, and the mean meaning score for the OC words was 0.99 . The meaning scores for the two wordtypes were also significantly different $[t(134)=-7.0$, $p<.001]$.

\section{Scanned Incidental Encoding Tasks}

fMRI data were acquired during four event-related runs. Each run consisted of 27 OD word trials, 27 OC word trials, and 27 fixation trials. The presentation order of these trials was constructed such that every trial type was equally likely to be preceded and followed by every other trial type (Buckner et al., 1998). Two buffer word trials were presented before and after each pseudorandom trial sequence. Data from buffer trials were not analyzed. Four fixation trials were presented at the beginning and at the end of each scanning run. During fixation, a plus sign was presented centrally. Words were presented centrally for $2350 \mathrm{msec}$, followed by $150 \mathrm{msec}$ of fixation. Participants performed the abstract/concrete task for two runs and the long vowel/short vowel task for two runs. Task and stimulus presentation order was counterbalanced across participants. Participants indicated their responses by making right-handed keypresses on a custom-made fiber-optic response box.

\section{Postscan Retrieval Test}

After leaving the scanner, participants performed a surprise recognition memory test ( $\sim 10 \mathrm{~min}$ delay). The words shown during incidental encoding and 54 new words (27 OD and 27 matched OC) were presented. The old and new words were randomly intermixed. Participants indicated their memory for each word by making a remember, know, new, or guess response.

\section{fMRI Data Acquisition}

Scanning was performed using a Siemens 1.5-T Vision scanner (Erlangen, Germany). High-resolution structural images $(1 \times 1 \times 1.25 \mathrm{~mm})$ were acquired using a T1-weighted MP-RAGE sequence $(\mathrm{TR}=9.7 \mathrm{msec}, \mathrm{TE}=$ $4 \mathrm{msec}$, flip angle $=10^{\circ}, \mathrm{TI}=20 \mathrm{msec}$, TD $=500 \mathrm{msec}$ ). Functional images were acquired using an asymmetric spin-echo echo-planar sequence sensitive to blood oxygen level-dependent (BOLD) contrast (T2 ${ }^{*}$; TR $=2.5 \mathrm{sec}$, $\mathrm{TE}=37 \mathrm{msec}$ ). Four functional runs of 93 whole-brain (16 contiguous $8-\mathrm{mm}$ axial slices oriented parallel to the AC-PC plane; $3.75 \times 3.75 \mathrm{~mm}$ in-plane resolution) images were collected per participant. The first four images in each run were discarded to allow T1 magnetization to stabilize.

\section{fMRI Data Analysis}

fMRI data were preprocessed to remove noise and artifacts (see Maccotta, Zacks, \& Buckner, 2001 for method details). Data were motion-corrected, adjusted for slice timing differences, transformed into the stereotaxic atlas space of Talairach and Tournoux (1998) using 2-mm isotropic voxels, and smoothed using a two-voxel isotropic Hanning filter. The data were analyzed using the general linear model implemented in an in-house analysis and display package (Miezin, Maccotta, Ollinger, Petersen, \& Buckner, 2000). Run mean and slope were coded as effects of no interest. For each participant, the BOLD response for each trial type was estimated by a different regressor (delta function) for each of the seven timepoints immediately after each stimulus onset.

\section{Hypothesis-driven Regional Analyses}

Hypothesis-driven analyses were performed on four predefined regions. The peak Talairach and Tournoux (1988) coordinates for these regions were $-45,35,-4$ (left BA 45/47); - 47, 17, 24 (left BA 44); - 51, - 55, 2 (left BA 21); and 47, 17, 24 (right BA 44). Percent signal change estimates were calculated by averaging across all voxels within each region for each condition and for each participant. Response magnitude estimates were calculated by subtracting the baseline signal response (average of timepoints 0 and $15 \mathrm{sec}$ ) from the peak signal response (average of timepoints 5 and $7.5 \mathrm{sec}$ ). 
The magnitude estimates for each participant were entered into a mixed-effects model, and specific comparisons were conducted using ANOVAs and paired post hoc $t$ tests.

\section{Whole-brain Exploratory Analyses}

Whole-brain exploratory analyses were conducted using mixed-effects $t$ tests performed on each voxel. Contrasts of interest were regressed against a set of five timelagged (1-sec offset) gamma functions (Boynton, Engel, Glover, \& Heeger, 1996). These contrasts were used to compute cross-correlation magnitudes for each trial condition as the inner product of the estimated time course and a vector of contrast weights modeling the hemodynamic response function. The cross-correlation magnitudes for the participants were then entered into the mixed-effects $t$ tests. Resulting $t$ statistics were converted to $z$ statistics and plotted over structural images created by averaging data from the 25 participants. The statistical significance criterion for the activation maps was set to $p<.05$, Monte Carlocorrected for multiple comparisons $(t=3.0$, cluster size of at least 21 voxels).

\section{Orthographic Distinctiveness Effect Regional Analyses}

Six regions were identified from the whole-brain functional activation map of regions demonstrating greater hemodynamic responses for OD than for OC words for regional analyses of the orthographic distinctiveness effect. An automated algorithm identified activation peaks. ROIs were then grown that included all continuous voxels within $12 \mathrm{~mm}$ of an activation peak, masked by the functional activation map. Response magnitude estimates were calculated by subtracting the baseline signal response from the peak signal response. The magnitude estimates for each participant were entered into a mixed-effects model, and specific comparisons were conducted using ANOVAs and paired post hoc $t$ tests.

\section{Projection to Cortical Flat Maps}

The distinct $>$ common word activation map was projected onto a cortical surface representation with human retinotopically defined visual regions using Caret and Surefit software (Van Essen, 2002; Van Essen et al., 2001; http://brainmap.wustl.edu/caret; see Wheeler \& Buckner, 2003, for projection method details). The location of the "visual word form area" comes from a meta-analysis of 35 word and pseudoword reading studies (Jobard, Crivello, \& Tzourio-Mazoyer, 2003) (Figure 7 , region A). Activity in the left occipitotemporal cortex (mean coordinates -44, -57, - 10; converted to Talairach \& Tournoux, 1988, space using mni2tal; see www.mrc-cbu.cam.ac.uk/Imaging/Common/mnispace. shtml) was found in multiple studies. The left medial extrastriate activation foci $(-29,-65,2 ;-21,-75,2$; $-21,-53,6$; Figure 7 , region B) come from a study by Petersen et al. (1990) (coordinates converted into Talairach \& Tournoux, 1988, space by Price et al., 1994).

\section{Acknowledgments}

We thank Erica Daiell, Lauren Cherry, Ben Shannon, Kate O'Brien, and Brian Gold for assistance with data collection and analysis. We also thank Reed Hunt for providing word stimuli, and Lisa Geraci and Jeff Toth for helpful discussion. This research was supported by a W.M. Keck Fellowship (BK), the Howard Hughes Medical Institute, the James S. McDonnell Foundation Program in Cognitive Neuroscience, and the National Institute of Mental Health (MH57506).

Reprint requests should be sent to Brenda A. Kirchhoff, Washington University, Psychology Department, Campus Box 1125, One Brookings Drive, St. Louis, MO 63130, or via e-mail: bkirchho@artsci.wustl.edu.

The data reported in this experiment have been deposited with the fMRI Data Center archive (www.fmridc.org). The accession number is 2-2005-119AG.

\section{REFERENCES}

Baker, J. T., Sanders, A. L., Maccotta, L., \& Buckner, R. L. (2001). Neural correlates of verbal memory encoding during semantic and structural processing tasks. NeuroReport. 12, 1251-1256.

Binder, J. R., McKiernan, K. A., Parsons, M. E., Westbury, C. F., Possing, E. T., Kaufman, J. N., \& Buchanan, L. (2003). Neural correlates of lexical access during visual word recognition. Journal of Cognitive Neuroscience, 15, 372-393.

Boynton, G. M., Engel, S. A., Glover, G. H., \& Heeger, D. J. (1996). Linear systems analysis of functional magnetic resonance imaging in human V1. Journal of Neuroscience, 16, 4207-4221.

Brewer, J. B., Zhao, Z., Desmond, J. E., Glover, G. H., \& Gabrieli, J. D. E. (1998). Making memories: Brain activity that predicts how well visual experience will be remembered. Science, 281, 1185-1187.

Buckner, R. L., Goodman, J., Burock, M., Rotte, M., Koutstaal, W., Schacter, D., Rosen, B., \& Dale, A. M. (1998). Functional-anatomic correlates of object priming in humans revealed by rapid presentation event-related fMRI. Neuron, 20, 285-296.

Chee, M. W. L., Goh, J. O. S., Lim, Y., Graham, S., \& Lee, K. (2004). Recognition memory for studied words is determined by cortical activation differences at encoding but not during retrieval. Neuroimage, 22, 1456-1465.

Chee, M. W. L., Westphal, C., Goh, J., Graham, S., \& Song, A. W. (2003). Word frequency and subsequent memory effects studied using event-related fMRI. Neuroimage, 20, 1042-1051.

Cohen, L., \& Dehaene, S. (2004). Specialization within the ventral stream: The case for the visual word form area. Neuroimage, 22, 466-476.

Cohen, L., Dehaene, S., Naccache, L., Lehericy, S., DehaeneLambertz, G., Henaff, M., \& Michel, F. (2000). The visual word form area: Spatial and temporal characterization of an initial stage of reading in normal subjects and posterior split-brain patients. Brain, 123, 291-307. 
Craik, F. I. M., \& Lockhart, R. S. (1972). Levels of processing: A framework for memory research. Journal of Verbal Learning and Verbal Behavior, 11, 671-684.

Craik, F. I. M., \& Tulving, E. (1975). Depth of processing and the retention of words in episodic memory. Journal of Experimental Psvchologv: General, 104, 268-294.

Demb, J. B., Desmond, J. E., Wagner, A. D., Vaidya, C. J., Glover, G. H., \& Gabrieli, J. D. E. (1995). Semantic encoding and retrieval in the left inferior prefrontal cortex: A functional MRI study of task difficulty and process specificity. Journal of Neuroscience, 15, 5870-5878.

Fabiani, M., \& Donchin, E. (1995). Encoding processes and memory organization: A model of the von Restorff effect. Journal of Experimental Psychology: Learning. Memorv. and Cognition, 21, 224-240.

Fiebach, C. J., Friederici, A. D., Muller, K., \& von Cramon, D. Y. (2002). fMRI evidence for dual routes to the mental lexicon in visual word recognition. Journal of Cognitive Neuroscience, 14, 11-23.

Fiez, J. A., Balota, D. A., Raichle, M. E., \& Petersen, S. E. (1999). Effects of lexicality, frequency, and spelling-to-sound consistency on the functional anatomy of reading. Neuron. 24, 205-218.

Gabrieli, J. D. E., Desmond, J. E., Demb, J. B., Wagner, A. D., Stone, M. V., Vaidya, C. J., \& Glover, G. H. (1996). Functional magnetic resonance imaging of semantic memory processes in the frontal lobes. Psychological Science, 7, 278-283.

Gardiner, J. M. (1988). Functional aspects of recollective experience. Memory \& Cognition, 16, 309-313.

Geraci, L., \& Rajaram, S. (2002). The orthographic distinctiveness effect on direct and indirect tests of memory: Delineating the awareness and processing requirements. Journal of Memory and Language, 47, 273-291.

Gold, B. T., \& Buckner, R. L. (2002). Common prefrontal regions coactivate with dissociable posterior regions during controlled semantic and phonological tasks. Neuron, 35 , 803-812.

Grill-Spector, K., Kushnir, T., Edelman, S., Itzchak, Y., \& Malach, R. (1998). Cue-invariant activation in object-related areas of the human occipital lobe. Neuron, 21, 191-202.

Grill-Spector, K., Kushnir, T., Hendler, T., \& Malach, R. (2000). The dynamics of object-selective activation correlate with recognition performance in humans. Nature Neuroscience, 3, 837-843.

Hunt, R. R., \& Elliott, J. M. (1980). The role of nonsemantic information in memory: Orthographic distinctiveness effects on retention. Iournal of Experimental Psychology: General. 109, 49-74.

Hunt, R. R., \& Mitchell, D. B. (1978). Specificity in nonsemantic orienting tasks and distinctive memory traces. Iournal of Experimental Psychologv: Human Learning and Memory, 4, 121-135.

Hunt, R. R., \& Mitchell, D. B. (1982). Independent effects of semantic and nonsemantic distinctiveness. Journal of Experimental Psychologv: Learning. Memorv. and Cognition, 8, 81-87.

Hunt, R. R., \& Toth, J. P. (1990). Perceptual identification, fragment completion, and free recall: Concepts and data. Iournal of Experimental Psychology: Learning. Memorv. and Cognition, 16, 282-290.

Hyde, T. S., \& Jenkins, J. J. (1969). Differential effects of incidental tasks on the organization of recall of a list of highly associated words. Iournal of Experimental Psvchologv, 82, 472-481.

Jacoby, L. L. (1991). A process dissociation framework: Separating automatic from intentional uses of memory. Lournal of Memory and Language, 30, 513-541.

Jobard, G., Crivello, F., \& Tzourio-Mazoyer, N. (2003).
Evaluation of the dual route theory of reading: A metanalysis of 35 neuroimaging studies. Neuroimage, 20, 693-712.

Kapur, S., Craik, F. I. M., Tulving, E., Wilson, A. A., Houle, S., \& Brown, G. M. (1994). Neuroanatomical correlates of encoding in episodic memory: Levels of processing effect. Proceedings of the National Academv of Sciences, U.S.A., 91, 2008-2011.

Karis, D., Fabiani, M., \& Donchin, E. (1984). "P300" and memory: Individual differences in the von Restorff effect. Cognitive Psychologv, 16, 177-216.

Kelley, W. M., Miezin, F. M., McDermott, K. B., Buckner, R. L., Raichle, M. E., Cohen, N. J., Ollinger, J. M., Akbudak, E. Conturo, T. E., Snyder, A. Z., \& Petersen, S. E. (1998). Hemispheric specialization in human dorsal frontal cortex and medial temporal lobe for verbal and nonverbal memory encoding. Neuron, 20, 927-936.

Kinoshita, S., \& Miller, M. (2000). The orthographic distinctiveness effect on fragment completion: Not implicit. Australian Journal of Psychology, 52, 63-68.

Kishiyama, M. M., \& Yonelinas, A. P. (in press). Novelty and recognition memory: Behavioral properties and neuro-anatomical substrates. In R. R. Hunt \& J. B. Worthen (Eds.), Perspectives on distinctiveness. London: Oxford University Press.

Kucera, H., \& Francis, W. N. (1967). Computational analysis of present-day American English. Providence: Brown University Press.

Logan, J. M., Sanders, A. L., Snyder, A. Z., Morris, J. C., \& Buckner, R. L. (2002). Under-recruitment and nonselective recruitment: Dissociable neural mechanisms associated with aging. Neuron, 33, 827-840.

Maccotta, L., Zacks, J. M., \& Buckner, R. L. (2001). Rapid self-paced event-related functional MRI: Feasibility and implications of stimulus- versus response-locked timing. Neuroimage, 14, 1105-1121.

Malach, R., Reppas, J. B., Benson, R. R., Kwong, K. K., Jiang, H., Kennedy, W. A., Ledden, P. J., Brady, T. J., Rosen, B. R., \& Tootell, R. B. H. (1995). Object-related activity revealed by functional magnetic resonance imaging in human occipital cortex. Proceedings of the National Academv of Sciences. U.S.A., 92, 8135-8139.

Mandler, G. (1980). Recognizing: The judgment of previous occurrence. Psychological Review, 87, 252-271.

Michelon, P., Snyder, A. Z., Buckner, R. L., McAvoy, M., \& Zacks, J. M. (2003). Neural correlates of incongruous visual information: An event-related fMRI study. Neuroimage, 19, $1612-1626$.

Miezin, F. M., Maccotta, L., Ollinger, J. M., Petersen, S. E., \& Buckner, R. L. (2000). Characterizing the hemodynamic response: Effects of presentation rate, sampling procedure, and the possibility of ordering brain activity based on relative timing. Neuroimage, 11, 735-759.

Morcom, A. M., Good, C. D., Frackowiak, R. S. J., \& Rugg, M. D. (2003). Age effects on the neural correlates of successful memory encoding. Brain, 126, 213-229.

Morris, C. D., Bransford, J. D., \& Franks, J. J. (1977). Levels of processing versus transfer appropriate processing. Journal of Verbal Learning and Verbal Behavior, 16, 519-533.

Otten, L. J., Henson, R. N. A., \& Rugg, M. D. (2001). Depth of processing effects on neural correlates of memory encoding: Relationship between findings from across- and within-task comparisons. Brain, 124, 399-412.

Petersen, S. E., Fox, P. T., Snyder, A. Z., \& Raichle, M. E. (1990). Activation of extrastriate and frontal cortical areas by visual words and word-like stimuli. Science, 249, 1041-1044.

Poldrack, R. A., Wagner, A. D., Prull, M. W., Desmond, J. E., Glover, G. H., \& Gabrieli, J. D. E. (1999). Functional 
specialization for semantic and phonological processing in the left inferior prefrontal cortex. Neuroimage, 10, 15-35.

Price, C. J., \& Devlin, J. T. (2004). The pro and cons of labelling a left occipitotemporal region: "The visual word form area". Neuroimage, 22, 477-479.

Price, C. J., Moore, C. J., Humphreys, G. W., \& Wise, R. J. S. (1997). Segregating semantic from phonological processes during reading. Journal of Cognitive Neuroscience, 9, $727-733$.

Price, C. J., Wise, R. J. S., Watson, J. D. G., Patterson, K., Howard, D., \& Frackowiak, R. S. J. (1994). Brain activity during reading. The effects of exposure duration and task. Brain, 117, 1255-1269.

Rajaram, S. (1998). The effects of conceptual salience and perceptual distinctiveness on conscious recollection. Psychonomic Bulletin \& Review, 5, 71-78.

Roskies, A. L., Fiez, J. A., Balota, D. A., Raichle, M. E., \& Petersen, S. E. (2001). Task-dependent modulation of regions in the left inferior frontal cortex during semantic processing. Journal of Cognitive Neuroscience, 13, 829-843.

Schmidt, S. R. (1991). Can we have a distinctive theory of memory? Memory \& Cognition, 19, 523-542.

Strange, B. A., Henson, R. N. A., Friston, K. J., \& Dolan, R. J. (2000). Brain mechanisms for detecting perceptual, semantic, and emotional deviance. Neuroimage, 12 , 425-433.

Talairach, J., \& Tournoux, P. (1988). Co-planar stereotaxic atlas of the buman brain. New York: Thieme Medical Publishers.

Tootell, R. B. H., \& Hadjikhani, N. (2001). Where is "dorsal V4" in human visual cortex? Retinotopic, topographic and functional evidence. Cerebral Cortex, 11, 298-311.

Tulving, E. (1985). Memory and consciousness. Canadian Psychology, 26, 1-12.

Van Essen, D. C. (2002). Windows on the brain: The emerging role of atlases and databases in neuroscience. Current Opinion in Neurobiology, 12, 574-579.
Van Essen, D. C. (2004). Organization of visual areas in macaque and human cerebral cortex. In L. Chalupa \& J. S. Werner (Eds.), The visual neurosciences (pp. 507-521). Cambridge: MIT Press.

Van Essen, D. C., Dickson, J., Harwell, J., Hanlon, D., Anderson, C. H., \& Drury, H. A. (2001). An integrated software system for surface-based analyses of cerebral cortex. Journal of American Medical Informatics Association, 41, 1359-1378. von Restorff, H. (1933). Uber die Wirkung von Bereichsbildungen im Spurenfeld. Psychologische Forschung, 18, 299-342.

Wagner, A. D., Poldrack, R. A., Eldridge, L. L., Desmond, J. E., Glover, G. H., \& Gabrieli, J. D. E. (1998). Material-specific lateralization of prefrontal activation during episodic encoding and retrieval. NeuroReport, 9, 3711-3717.

Wagner, A. D., Schacter, D. L., Rotte, M., Koutstaal, W., Maril, A., Dale, A. M., Rosen, B. R., \& Buckner, R. L. (1998). Building memories: Remembering and forgetting of verbal experiences as predicted by brain activity. Science, 281, 1188-1191.

Wheeler, M. E., \& Buckner, R. L. (2003). Functional dissociation among components of remembering: Control, perceived oldness, and content. Journal of Neuroscience, 23, 3869-3880.

Yonelinas, A. P. (2002). The nature of recollection and familiarity: A review of 30 years of research. Journal of Memory and Language, 46, 441-517.

Yonelinas, A. P., \& Jacoby, L. L. (1995). The relation between remembering and knowing as bases for recognition: Effects of size congruency. Iournal of Memory and Language, 34, 622-643.

Zechmeister, E. B. (1969). Orthographic distinctiveness. Lournal of Verbal Learning and Verbal Behavior, 8 , $754-761$.

Zechmeister, E. B. (1972). Orthographic distinctiveness as a variable in word recognition. American Journal of Psvchology, 85, 425-430. 
This article has been cited by:

1. Katherine R. Mickley Steinmetz, Elizabeth A. Kensinger. 2009. The effects of valence and arousal on the neural activity leading to subsequent memory. Psychophysiology 46:6, 1190-1199. [CrossRef]

2. Amy E. Booth. 2009. Causal Supports for Early Word Learning. Child Development 80:4, 1243-1250. [CrossRef] 